\title{
Shear Behaviour of Historic Masonry Made of Clay Bricks
}

\author{
R. Capozucca*
}

Structural Section of D.A.C.S., University Politecnica delle Marche, Ancona, Italy

\begin{abstract}
Historic masonry walls have demonstrated high vulnerability and low shear capacity when exposed to seismic actions. The behaviour of historic un-reinforced masonry (HURM) walls under combined compression and shear loading plays a fundamental role in the seismic verification of masonry buildings. Experimental investigations on historic masonry were carried out by the author on shear walls and triplets built with full clay bricks in scale $1: 3^{\text {rd }}$ to establish the shear behaviour of HURM walls. On the basis of experimental research, a shear criterion for HURM has been assumed. It appears that the shear strength of masonry increases with the pre-compression up to a limit and becomes constant at higher pre-compression. Finally, the experimental load-deflection relationship and cracking distribution along the surface of the shear walls have been compared with the theoretical results obtained by a non linear FE analysis of HURM walls and a good co-relation was found between them.
\end{abstract}

Keywords: Historic masonry, shear strength, shear tests, FE analysis.

\section{INTRODUCTION}

In many countries, a huge cultural heritage is preserved in the form of historic masonry buildings. Although these historic masonry structures are considered not to be resistant to earthquake loading, many have resisted the effect of seismic action without any damage. The knowledge of the behaviour of historic unreinforced masonry (HURM) under combined compression and shear is a major criterion for defining the adequate restoration technique or for examining the capacity of historical buildings. The failure of masonry walls under combined compression and shear represents, in fact, a dangerous failure mechanism of historic buildings, especially, under seismic actions. The mechanism of resistance in shear depends on the geometry of masonry walls, their boundary conditions, the magnitude of the vertical loads and, finally, on the characteristics of the interface bond between bricks or stones and mortar. This paper presents main results obtained by an extensive experimental program to study the ultimate shear strength of a historic masonry subjected to pre-compression. The experimental research foresees shear tests on walls and triplets. Walls of rectangular section under in plane loading are generally meant to simulate the actual loading conditions encountered in shear walls. Unfortunately the rectangular wall section for shear test will invariably fail initially in tension before final failure in shear. As a result the whole section will not be resisting the shear, hence in the experimental research a modified Tsection was used so that the failure will be due to shear and not initiated by tension. Walls were made from the bricks obtained from an ancient Italian building using full clay bricks in scale $1: 3^{\text {rd }}$. On the basis of experimental research on shear walls, a shear criterion for HURM has been evaluated. It appears that the shear strength of masonry increases

*Address correspondence to this author at the Structural Section of D.A.C.S., University Politecnica delle Marche, Ancona, Italy;

Tel: 071.2204570; E-mail: r.capozucca@univpm.it with the pre-compression up to a limit and becomes constant at higher pre-compression. RILEM [1] recommends the use of triplets to obtain the shear strength of masonry. Triplets built with the same historic bricks and mortar used in the walls were tested in a second phase of experimental research. A normal linear regression between data from triplet tests permitted to calculate the initial strength of masonry in absence of vertical stress and the coefficient of friction as a typical Coulomb's criterion. The results of triplet and shear tests on walls are compared and discussed. Finally, a theoretical non linear analysis by FEM of tested walls permitted to compare theoretical displacements with experimental load-deflection relationship and describe the development of the cracking.

\section{SHEAR BEHAVIOUR OF MASONRY}

Several works were done in the past to establish the behaviour of URM subjected to in-plane loading. In the following, the most common models present in the literature are discussed. Benjamin and Williams [2] investigated the shear behaviour of full-scale and model brick masonry walls. Their results led to an important conclusion that the scale effect has no significance on the ultimate strength in shear. Sinha [3] tested couplet made with bricks having different moisture content. Sinha and Hendry [4] presented the test results of six-one storey shear walls with opening subjected to precompression. The model was in $1: 6^{\text {th }}$ scale subjected to raking load with varying degree of pre-compression. They proposed a three phase shear failure criterion based on experimental results due to different mechanisms: shear slip at the interface up to a limit of pre-compression; diagonal tensile failure of masonry for a certain range of pre-compression; solely frictional phase limited by the compressive strength of the masonry. Six full-scale single-storey structures with and without openings subjected to combined compression and shear were also tested by Hendry and Sinha [5]. The results confirmed the earlier work done on the model and reinforced the findings that the scale effect is not significant. Turnšek 
and Čačovič [6] presented some experimental results about failure and deformations of walls due to combined compression and shear stresses. Failure was caused to diagonal crack or two crossed diagonal cracks. They proposed a shear strength criterion considering only the tensile stress linked to the aspect ratio of the masonry panel. Yokel and Fattal [7] advanced a failure hypothesis for brick masonry shear walls on the basis of the test results. Diagonal compressive load and pre-compression normal to bed joint was applied. The observed failures suggested a value of friction coefficient and a coefficient for the change in failure mode depending on the tensile strength of the mortar and the interface bond strength between brick and mortar. Hendry [8] proposed a non-dimensional equations based on principal tensile stress to describe the shear behaviour. Drysdale et al. [9] reported the results of shear tests with and without pre-compression of brick specimens built with three different types of bricks and mortar. Some important results confirmed the behaviour at low pre-compression with a shear slip failure and shear bond strength is not related to compressive strength of mortar. Mann and Muller [10] established a failure theory based on the relationship between pre-compression and shear stress with the assumption that no shear stress can be transferred through the vertical joints between the bricks. The general behaviour of shear walls can be described as: a first phase, similar to the proposal of Sinha and Hendry [4], with friction failure of the bed joint in the area subject to a vertical stress minor than a fixed value; a second phase with cracking of the bricks in presence of moderate vertical stress and, finally, a third phase characterized by compression failure under very high vertical stress. A criterion for design practice was proposed by Benedetti and Tomaževič [11] based on tensile strength of masonry using a coefficient of shear stress distribution on section between $1 \div 1.5$. Other researchers [12-14] conducted a series of tests that permitted to control the influences of some parameters on the shear strength of URM. An experimental work with useful suggestions on the diagonal shear tests was developed by Collantes et al. [15]. Diagonal compression tests on square wallets of three different sizes were carried out; shear strength results obtained show a significant dependence of shear strength on

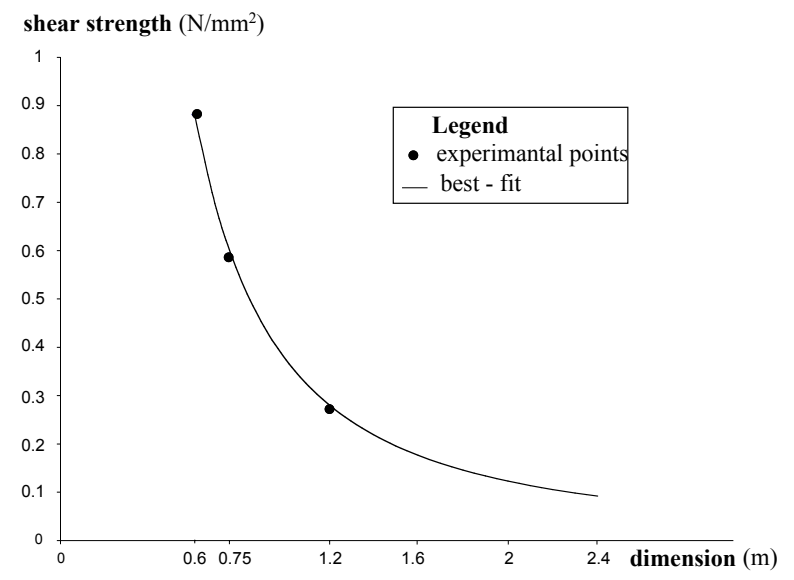

Fig. (1). Relationship between the shear strength and size of specimens under diagonal compression tests. the specimen size (Fig. 1). Magenes and Calvi [16] proposed a shear criterion based on tensile capacity of masonry walls introducing a coefficient $\mathrm{k}=1+\mathrm{h}_{0} / \mathrm{d}$, with $\mathrm{d}=$ width of wall and $\mathrm{h}_{0}=$ effective height of wall, in order to take into account both the slenderness influence and the boundary restraints.

Shubert et al. [17] analyzed shear strength by diagonal compression and results show the phenomena of constant shear (Fig. 2) above a value of pre-compression.

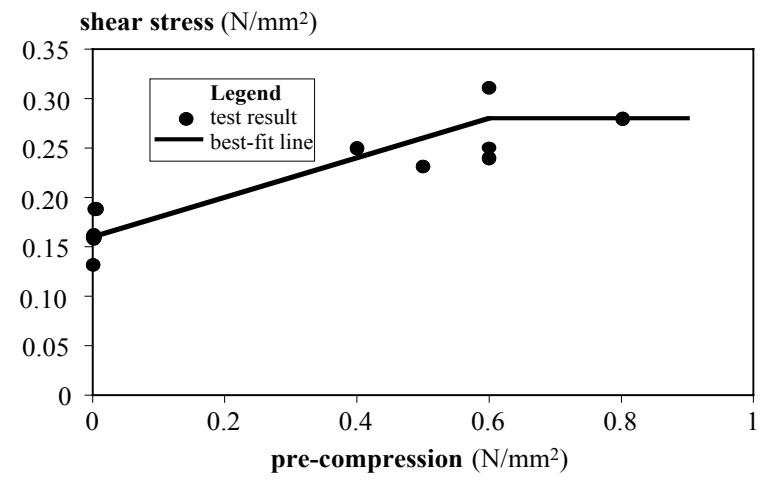

Fig. (2). Experimental shear strength value [17].

Although numerous experimental works to establish the behaviour of URM have been done and shear criteria were adopted in practice codes, similar experimental validation of shear criterion for HURM is lacking. The studies of historic masonry buildings have shown the great influence of the properties of materials and the construction technique on the shear response [18-21]. The analysis of HURM must take into account the actual mechanical characteristics of masonry of clay bricks and mortar including the method of its arrangement in the wall.

\section{SHEAR FAILURE CRITERIA}

From a large number of models and full-scale tests, the shear failure criteria foresee failure of URM along the joints of mortar and or through mortar joints and bricks. To describe shear failure with slip on mortar joints, it has been established in the European Code (EC6) [22] that the shear strength of masonry follows the Mohr-Coulomb law:

$$
\tau_{u}=\tau_{0}+\mu \cdot \sigma_{v}
$$

where: $\tau_{\mathrm{u}}=$ the average shear strength; $\tau_{0}=$ the average shear strength with zero pre-compression; $\sigma_{v}=$ the average compressive stress normal to the bed joint and, finally, $\mu=$ the coefficient of friction. It assumes that the masonry shear strength consists of initial bond strength between mortar and units. This criterion does not take into account the stress distribution within the panel and has not been validated for precompression higher than $2.0 \mathrm{~N} / \mathrm{mm}^{2}$. Diagonal cracking through joints and bricks is due to principal tensile stress as suggested by Hendry [8] who proposed the following nondimensional equation:

$$
\left.\frac{\tau_{u}}{f_{t}}=\sqrt{\left(\frac{\sigma_{v}}{f_{t}}\right.}+1\right)
$$


where: $f_{t}=$ principal tensile stress. Principal tensile stress is affected by the pre-compression normal to the bed-joint and may be represented by:

$f_{t}=f_{t 0}+\alpha \cdot \sigma_{v}$

where: $f_{t 0}=$ is the value of $f_{t}$ at zero pre-compression, equal to the ultimate shear stress $\tau_{0}$ in a pure shear; $\alpha=$ is a coefficient. Substituting the value of $f_{t}$ from Eq. (3) into Eq. (2):

$\tau_{u}^{2}=\tau_{0}^{2}+\tau_{0} \sigma_{v}+\alpha \cdot \sigma_{v}^{2}+2 \cdot \alpha \cdot \tau_{0} \cdot \sigma_{v}+\alpha^{2} \cdot \sigma_{v}^{2}$

For value of $\alpha$ taken as 0.05 [8], the Eq. (4) becomes:

$\tau_{u}^{2}=\tau_{0}^{2}+1.1 \cdot \tau_{0} \cdot \sigma_{v}+0.053 \cdot \sigma_{v}^{2}$

This relationship requires knowledge of only one parameter, i.e. the strength of masonry in pure shear. This can only be evaluated by simple triplet test with varying precompression. As recommended by RILEM [1], a normal linear regression between shear and pre-compression was done with the data obtained from triplet tests to determine both $\tau_{0}$ and $\mu$ so that Eqs. (1) and (5) may be adopted to describe shear strength of masonry under compression and shear.

Table 1. Experimental Shear Strength of HURM Walls

\begin{tabular}{|c|c|c|}
\hline HURM Walls & $\begin{array}{c}\text { Precompression } \\
\boldsymbol{\sigma}_{\mathbf{v}} \\
\left(\mathbf{N} / \mathbf{m m}^{2}\right)\end{array}$ & $\begin{array}{c}\text { Shear Strength } \\
\boldsymbol{\tau}_{\mathbf{u}} \\
\left(\mathbf{N} / \mathbf{m m}^{2}\right)\end{array}$ \\
\hline \hline P1 & 0.50 & 0.66 \\
\hline P2 & 0.75 & 0.68 \\
\hline P3 & 0.30 & - \\
\hline P4 & 0.30 & 0.54 \\
\hline P5 & 1.15 & 1.43 \\
\hline P6 & 2.25 & 1.90 \\
\hline P7 & 3.00 & 1.90 \\
\hline
\end{tabular}

EXPERIMENTAL SHEAR TESTS ON HURM WALLS AND TRIPLETS

An experimental procedure was adopted to establish the strength of HURM under combined compression and shear that may be used with a wide variety of masonry.

\section{Shear Tests on HURM Walls}

Many works [2, 4-5] have clearly shown that the strength of full scale walls in shear can be predicted by test on small scale model. Therefore, the test specimens were built with $1 / 3^{\text {rd }}$ scale bricks obtained from a full scale Italian Historic Building of $18^{\text {th }}$ Century. Experimental shear tests are carried out considering both triplets and walls. The ASTM [23] recommends testing square wall specimen in diagonal compression to obtain the shear strength. This type of test does not appear useful to describe the actual behaviour of HURM since the test results are affected significantly by the size of the specimen, as shown in Fig. (1). Besides, being the masonry a composite material with the weakest link at the interface of brick and mortar, which does not depend on the strength of mortar or the units, the strength depends on the angle of inclination of applied load to the bed joint [24]. Having considered all these facts, the HURM walls were designed as $\mathrm{T}$-shape section so that no negligible tension develops at the base of the walls at ultimate and the failure is initiated only due to shear. The test HURM walls were built with clay bricks of dimensions $100 \cdot 50 \cdot 17 \mathrm{~mm}$. Tests were carried out preliminary to establish the strength of clay bricks and mortar. The average compressive strength of the clay bricks was $34.3 \mathrm{~N} / \mathrm{mm}^{2}$. A cement : lime : sand (1:1:5) mortar by volume was used for the construction of the specimens.

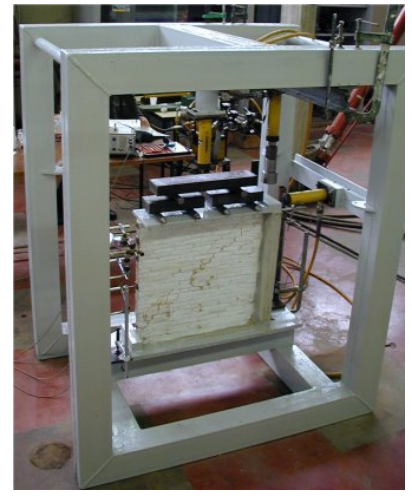

Fig. (3). Test structure and the loading frame.

The wallet specimens were tested in compression to obtain the modulus of elasticity and strength in two orthogonal directions i.e. perpendicular $\left(\mathrm{f}_{\mathrm{c}}=17.4 \mathrm{~N} / \mathrm{mm}^{2}\right.$, $\left.\mathrm{E}_{\perp}=11.65 \mathrm{kN} / \mathrm{mm}^{2}\right)$ and parallel $\left(\mathrm{f}_{\mathrm{c}}=21.04 \quad \mathrm{~N} / \mathrm{mm}^{2}\right.$, $\mathrm{E}_{/ /}=10.58 \mathrm{kN} / \mathrm{mm}^{2}$ ) to bed joint (Figs. (4a) and (b)). The average $\mathrm{E}$ value obtained on tested prisms is $11.12 \mathrm{kN} / \mathrm{mm}^{2}$. The Brazilian test on a square panel with mortar bed inclined to $45^{\circ}$ to the point load was done to obtain the diagonal tensile strength. The diagonal tensile strength was $\mathrm{f}_{\mathrm{t}}=0.42$ $\mathrm{N} / \mathrm{mm}^{2}$.
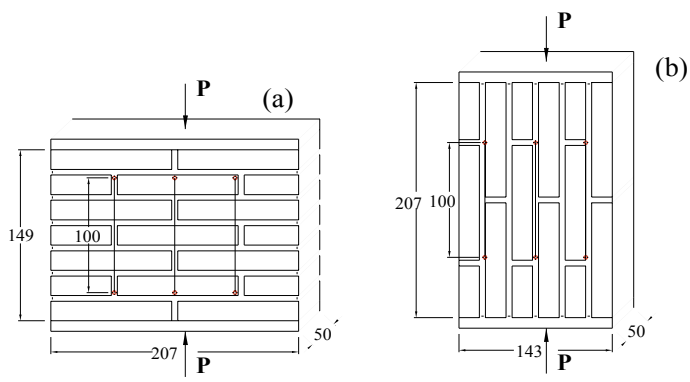

Fig. (4). Wallets subjected to compression in two orthogonal directions.

Seven single-storey structures were built and tested in a special frame (Fig. 3). The pre-compression varied from 0.3 to $3.0 \mathrm{~N} / \mathrm{mm}^{2}$ (Table. 1). The dimensions of the tested walls were $630 \mathrm{~mm} \cdot 630 \mathrm{~mm} \cdot 50 \mathrm{~mm}(1 \cdot \mathrm{h} \cdot \mathrm{t})$. Three separate jacks were used to apply the loading and the loads were monitored by three load-cells. Five electrical transducers (1-5) were used to measure the deflection at various level of the structure as shown in (Fig. 5). A $100-\mathrm{mm}$ 'deformometer' was used to measure the vertical strains at four positions along the length designated by letter $\mathrm{A}$ to $\mathrm{H}$ on both faces of the 
shear wall as shown in Fig. (5). The principal strains were measured by Rosetta in the centre of the wall on both faces. Before the application of shear load, full pre-compression was applied to the flange and the web of the wall.

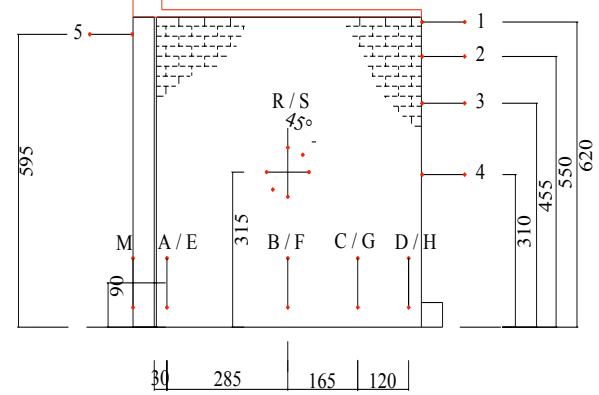

Fig. (5). Positions of measuring instruments for strains and deflections.

The shear force was applied in stages till failure and deflections and strains were measured at various stages till it became unsafe to take the readings. Results of the shear strength are shown in the Table. 1. The typical failure of walls in shear and deflections are shown in Figs. $(6,7)$ and (8) for, respectively, P1, P2 and P5. Walls P1 and P2 are subjected to relatively low values of pre-compression, respectively, equal to 0.50 and $0.75 \mathrm{~N} / \mathrm{mm}^{2}$, while P5 was tested under a high value of pre-compression equal to 1.15 $\mathrm{N} / \mathrm{mm}^{2}$. It is known that brickwork subjected to combined stress exhibits two distinct types of failure: (a) due to shear failure at the interface governed of initial bond shear and friction between brick and mortar; (b) due to cracking through bricks and mortar governed by the constant maximum tensile strain or stress $[3,8,10]$.

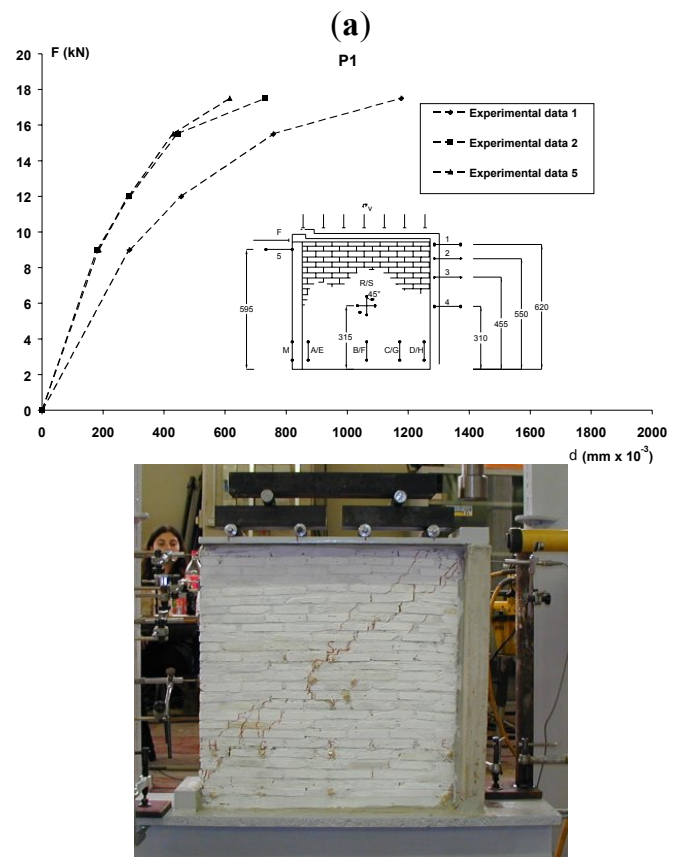

(b)

Fig. (6). (a) Diagrams of lateral load, F, vs. deflections; (b) model $\mathrm{P} 1$ at the failure with cracks between the mortar joints. (a)

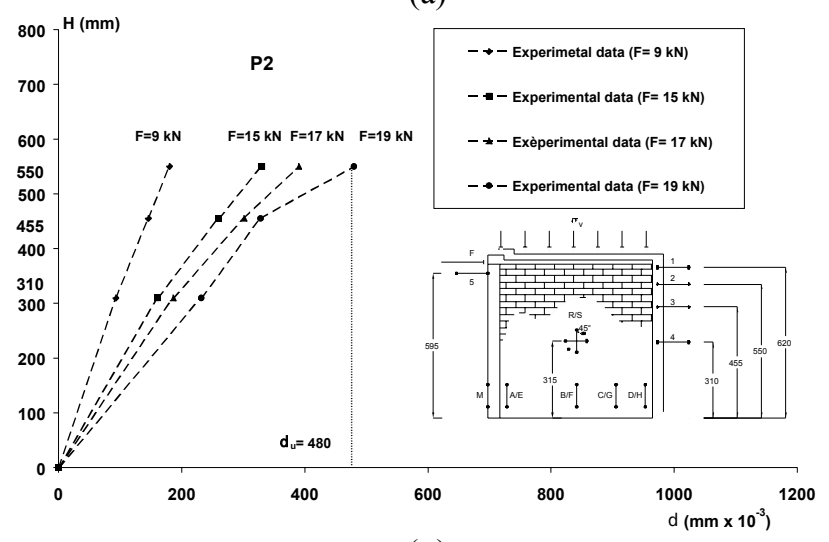

(a)

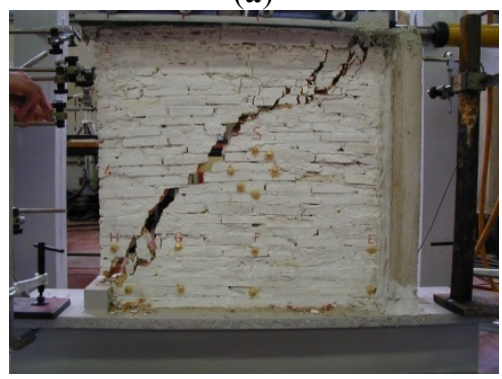

(b)

Fig. (7). (a) Diagrams of deflections $\delta$ on the height of wall (points $2,3,4$ ); (b) model P2 at the failure with cracks between the mortar joints and bricks.

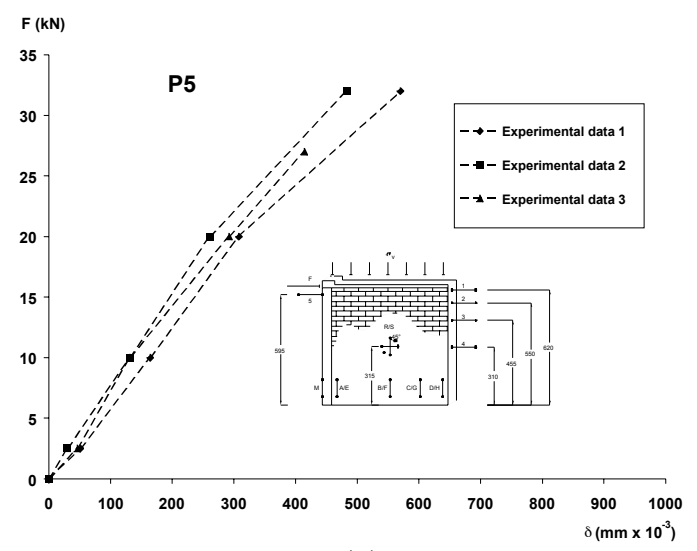

(a)

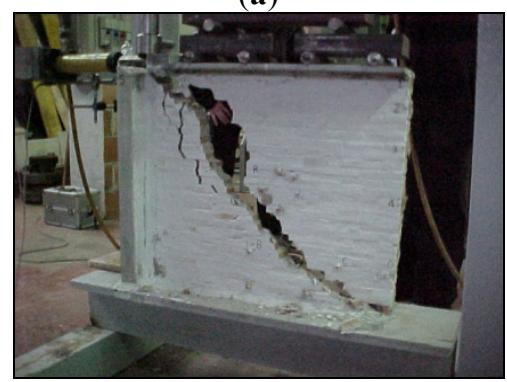

(b)

Fig. (8). (a) Diagrams of lateral load, F, vs. deflections, $\delta$; (b) model P5 at the failure with cracks between the mortar joints and bricks. 
In Figs. (6) to (8) the experimental diagrams of shear load, F, versus deflections of lateral edge and cracking failure modes of walls are shown. It may be noted that experimental diagrams are non-linear when pre-compression is low (walls P1 and P2) and become quasi linear for P5 subjected to a constant high value of pre-compression.

\section{Shear Tests on HURM Triplets}

Figs. 9(a), (b) and (c) show, respectively, the experimental set up for triplets test; typical specimen with nominal dimensions of units and, finally, historic bricks.
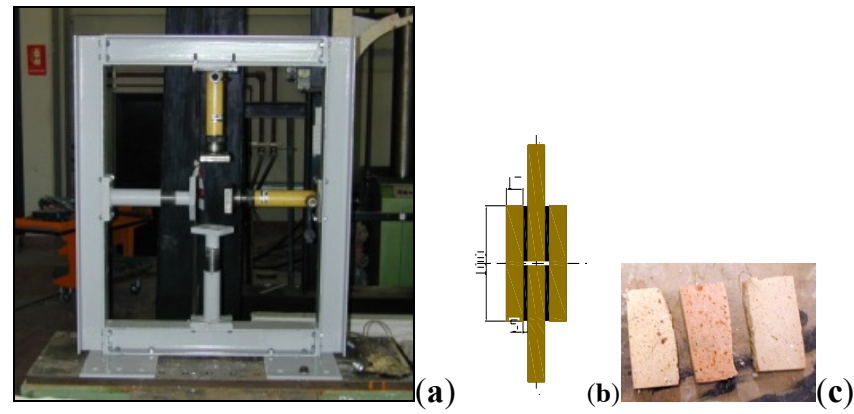

Fig. (9). (a) Set up for shear tests; (b) triplets with dimensions of bricks; (c) historic bricks in scale 1:3 ${ }^{\text {rd }}$.

Two independent jacks connected to separate pumps applied pre-compression and shear loads (Fig. 9a). The precompression was applied by jack placed horizontally monitored by a load cell. The pre-compression was kept constant during each test. Shear tests on triplets regarded three types of specimens with different quality of mortar. Experimental data of mortar strength are shown in Table. 2. 24 specimens of T-triplets; 8 specimens of S-triplets and 8 specimens of Rtriplets were tested. At low pre-compression the failure was at the interface between brick and mortar while at high precompression the brick failed. In Figs. $(\mathbf{1 0}, \mathbf{1 1})$ and $(\mathbf{1 2})$ the experimental linear curves, as suggested by RILEM [1] obtained from results of $\mathrm{T}, \mathrm{S}$ and $\mathrm{R}$ triplets, are shown.

Table 2. Triplets and Mortar Strength.

\begin{tabular}{|c|c|c|c|}
\hline Triplets & T & S & R \\
\hline \hline $\begin{array}{c}\text { mortar (cement:lime:sand) } \\
\text { compressive strength of mortar } \\
\left(\mathrm{N} / \mathrm{mm}^{2}\right)\end{array}$ & $1: 1: 5$ & $1: 1 / 4: 5$ & $0: 1: 5$ \\
\hline $\begin{array}{c}\text { tensile strength } \\
\left.\text { by bending of mortar( } \mathrm{N} / \mathrm{mm}^{2}\right)\end{array}$ & 0.70 & 0.30 & 0.16 \\
\hline
\end{tabular}

\section{Discussion of Experimental Results}

Shear strength obtained both with shear tests on T-triplets and walls are compared and discussed. Accordingly, the values work out to be: the initial shear strength of T-triplets is $\tau_{0}$ $=0.31 \mathrm{~N} / \mathrm{mm}^{2}$ and the coefficient of friction is about $\mu=0.60$ (Fig. 10).

Doing similar exercise with shear tests on walls and ignoring the result of wall P7 because the shear strength re- mains constant, the values are: the initial shear strength $\tau_{0}=$ $0.31 \mathrm{~N} / \mathrm{mm}^{2}$ and the coefficient of friction equal to $\mu=0.74$ (Fig. 13).

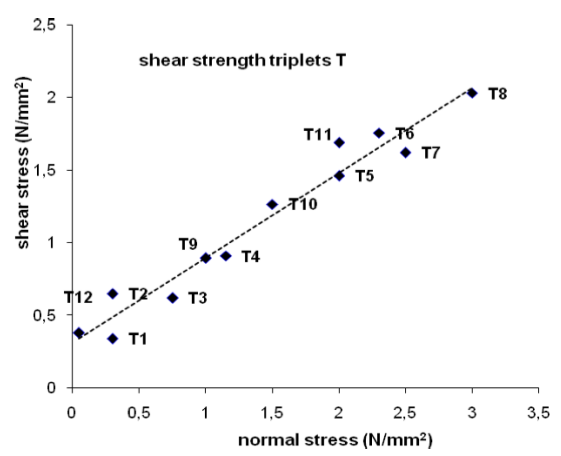

Fig. (10). Exp. results of shear tests on T-triplets.

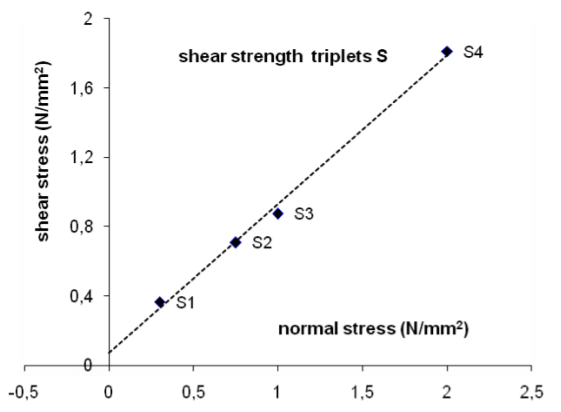

Fig. (11). Exp. results of shear tests on S-triplets.

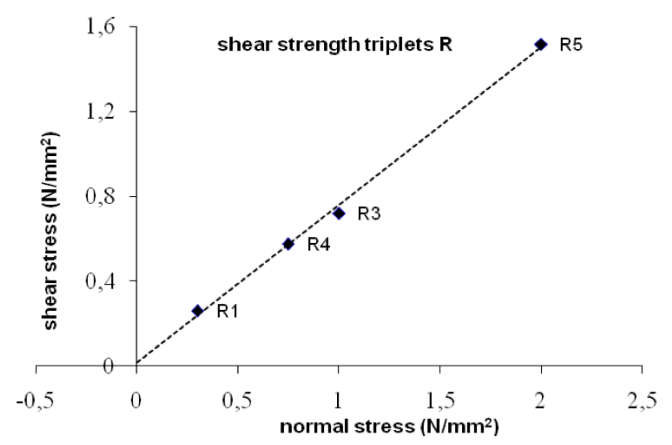

Fig. (12). Exp. results of shear tests on R-triplets.

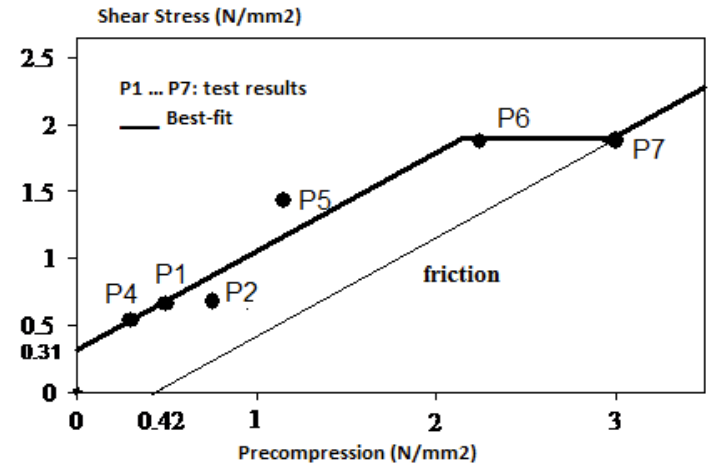


Fig. (13). Experimental shear criterion for HURM.

The value of the coefficient of friction usually suggested in the European code [22] is equal to 0.4 minor than the value that may be evaluated in the experimental shear tests. The shear stress increases linearly with increasing precompression up to a limit; this limit is equal to $2.15 \mathrm{~N} / \mathrm{mm}^{2}$. On critical examination of the test results on walls, it appears that the initial bond shear reduces to zero at higher precompression and the actual coefficient of friction, $\mu$, decreases. Assuming that the coefficient of friction remains constant, the value of $0.42 \mathrm{~N} / \mathrm{mm}^{2}$ is determinate on the normal stress axis equal to $f_{t}$ the tensile strength of masonry (Fig. 13). The value of the pre-compressions $\sigma_{\mathrm{y} 1}$ and $\sigma_{\mathrm{y} 2}$ when shear becomes constant for the current work appears to be $2.15 \mathrm{~N} / \mathrm{mm}^{2}$ to $3.0 \mathrm{~N} / \mathrm{mm}^{2}$ respectively. At the precompression stresses $\sigma_{\mathrm{y} 1}$ and $\sigma_{\mathrm{y} 2}$ the transitional phase of the failure starts and within these limits failure of HURM walls occurred by the maximum tensile strength. This behaviour was found by numerous researchers [5, 2, 9, 17] analysing shear test results showing this phenomena of constant shear (Fig. 13) over a range of pre-compression but this has been ignored or sometime a statistical best fit line has been drawn through the experimental points. Beyond this range of precompression, shear stress may increase linearly due to friction between two rigid bodies, i.e. brick and mortar. The general criterion for shear failure was formulated as follows:

$\begin{array}{ll}\tau_{u}=\tau_{0}+\mu \cdot \sigma_{v} & \sigma_{v} \leq \sigma_{y 1} \\ \tau=\mu \cdot\left(\sigma_{y 2}-f_{t}\right) & \sigma_{y 2} \leq \sigma_{v}\end{array}$

Both tests on triplets and walls may be used to determine shear criterion although the triplet tests, being a single joint tests, may not actually reflect the strength of the wall. At high pre-compression, the shear strength of wall may be not detected in the triplet tests.

\section{THEORETICAL ANALYSIS}

Masonry is a material which exhibits distinct directional properties due to mortar joints. In general, the approach towards its numerical representation can focus on the micromodelling of the individual components of unit and mortar, or on the macro-modelling of masonry as a composite material. For the objectives of this work, the theoretical analysis of HURM walls was developed by a macro-modelling, considering the masonry as a homogeneous material. The behaviour of full HURM walls was analyzed by a non linear procedure implemented in the finite element code ANSYS using solid finite elements.

Element solid 65 was adopted to model the web of wall. Flange and steel plate have been considered resistant to tension while, for the HURM of web, failure criteria to tension and compression were assumed. Cracking is shown by smeared crack view on the specimen surface; for each step the stiffness of material is modified taking into account the cracking. The comparison of theoretical deflection diagrams for the top of wall with experimental displacements is shown in Fig. (14) for walls P1, P4, P5 and P6. It may be noted that there is a good agreement between the theoretical and experimental results of lateral displacements at the top of wall. In the case of walls under high vertical values of precompression, P5 and P6, the theoretical analysis is very close
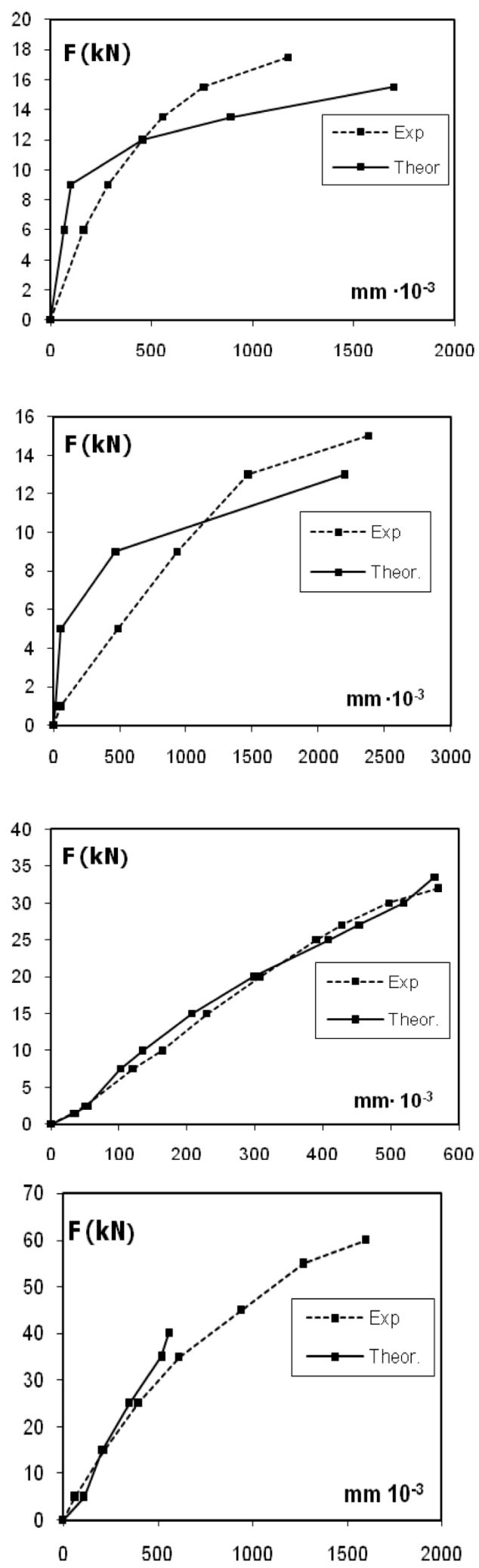

Fig. (14). Experimental and theoretical diagrams lateral load, F, vs. displacement at the top of HURM walls P1, P4, P5 and P6.

to experimental response, confirming that the behaviour of masonry under high pre-compression value is similar to a homogeneous material. Cracking failure at the ultimate load step is shown in Fig. (15a) for wall P5. The comparison with 

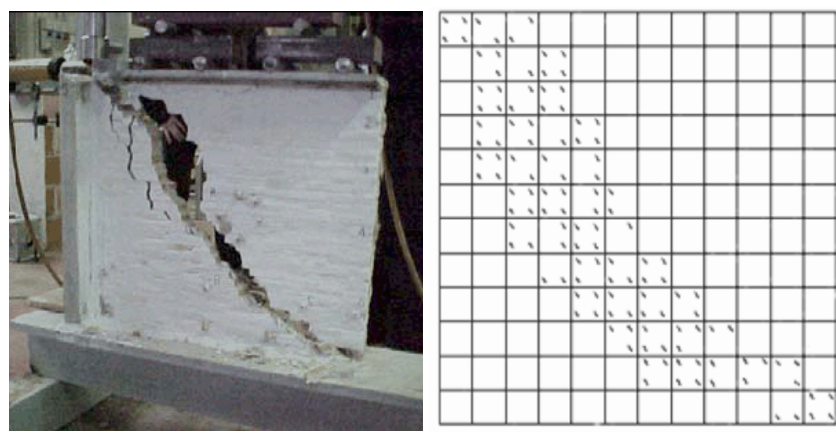

P5 (a)
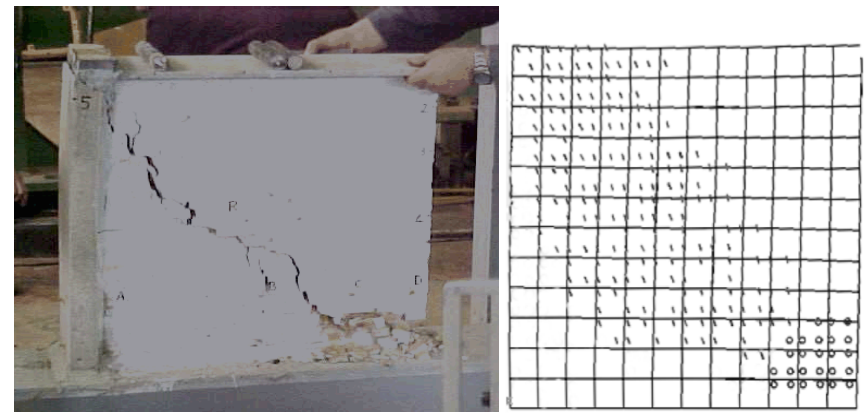

P6 (b)

Fig. (15). Comparison of experimental and theoretical cracking failure for (a) P5 and (b) P6 walls.

experimental view put on that during the tests the failure cracking developed with a limited diffusion of cracks on the diagonal. Analogous comments may be done by a comparison of theoretical and experimental cracking at failure for wall P6 (Fig. 15b) where is also well drawn the compression failure reached on the corner of wall.

\section{CONCLUSIONS}

From this study, general conclusions on the behaviour of HURM in shear can be drawn:

a. The shear strength of masonry increases linearly with pre-compression up to a limit.

b. At high pre-compression, the initial bond strength reduces to zero, thus there is no increase in shear strength. Beyond the shear strength is solely due to friction between brick and mortar separated by horizontal crack at the interface.

c. Different strength capacity of mortar has a great influence on the shear strength.

d. The analysis of walls subjected to in-plane loading may be developed adopting a non linear analysis procedure by FEM with macro-elements considering the masonry as an isotropic material.

\section{ACKNOWLEDGEMENTS}

The author thanks Emeritus Professor B.P. Sinha, University of Edinburgh, for his precious collaboration on experimental research and analysis of results.
The experimental research was financed by funds of University Politecnica of Marche.

\section{REFERENCES}

[1] T. C. Rilem, 127-MS Test, "Test for masonry materials and structures", Materials and Structures, vol. 29, pp. 459-47, 1996.

[2] R. Benjamin, and H. A. Williams, "The behaviour of one-story brick shear walls", Journal of Structural Engineering Division ASCE, vol. 84, no. 1723, pp. 1-30, 1985.

[3] B. P. Sinha, Model studies related to load-bearing brickwork. PhD Thesis, University of Edinburgh, UK, 1967.

[4] B. P. Sinha, and A. W. Hendry, Racking tests on storey-height shear-wall structures subjected to pre-compression, Proceedings of $2^{\text {nd }}$ International Brick Masonary Conference USA, Designing, Eng. and Constructing with masonry products, pp. 192-199, 1969.

[5] A. W. Hendry, and B. P. Sinha, Shear tests on full-scale singlestorey brickwork structures subjected to pre-compression. Journal Civil Eng. and Public Works Review, pp. 1339-1344, 1971.

[6] V. Turnesec, and F. Cacovic, Some experimental results on the strength of brick masonry walls, Proceedings of $2^{\text {nd }}$ International Brick Masonary Conference, UK, 1970, pp. 149-156.

[7] F. Y. Yokel, and S. G. Fattal, "Failure hypothesis for masonry shear walls", Journal of Structural Engineering Division ASCE, vol. 102, pp. 515-532, 1976.

[8] A. W. Hendry, "A note on the strength of brickwork in combined racking shear and compression", Proceedings of British Ceramic Society Load Bearing Brickwork, vol. 6, no. 27,pp. 47-52, 1978.

[9] R. G. Drysdale, R. Vanderkeyl, and A. A. Hamid, Shear strength of brick masonry joints. Proc. $5^{\text {th }}$ Int. Brick Masonry Conf., Washington, vol. 13, pp. 106-113, 1979.

[10] W. Mann, and H. Muller, "Failure of shear-stressed masonry", Proceedings of British Ceramic Society, vol. 27, pp. 223-235, 1980.

[11] D. Benedetti, and M. Tomazevic, "Sulla verifica sismica di costruzioni in muratura", Ingegneria Sismica, vol. 1, pp. 9-16, 1984. (in Italian). 
[12] P. Hofmann, and S. Stockl, "Tests on the shear-bond behaviour in the bed-joints of masonry", Masonry International, vol. 9, pp. 1-15, 1986.

[13] J. R. Riddington, M. Z. GhazaliI, Shear strength of masonry walls, Proceedings of $8^{\text {th }}$ International Brick/Block Masonry Conference Dublin, pp. 548-558, 1998.

[14] R. H. Atkinson, B. P. Amadei, S. Saeb, S. Sture, "Response of masonry bed joints in direct shear", Journal of Structural Engineering. $A S C E$, vol. 115, no. 9, pp. 2276-79, 1989.

[15] M. C. Collantes, L. S. Franco, and F.H. Sabbatici, Resistencia de aderencia ao cisalhamento da alvenaria estrutural nao armada de blocos ceramicos, Proceeding of $5^{\text {th }}$ International Seminar on Structure Masonry Developing Countries, Florianopolis, Brazil, 1994, p. 204-13 (in Portuguese).

[16] G. Magenes, G. M. Calvi, "Cyclic behaviour of brick masonry walls", Earthquake Engineering and Structural Dynamics, vol. 27, pp. 1091-1112, 1997.

[17] P. Schubert, and D. Bohene. Schubfestigkeit von Mauerwerk aus Leichtbetonsteinen. das Mauerwerk Heft 3, Ernst \& John, 2002, p. 98-102. (In Deutschland).

[18] R. Capozucca, and B. P. Sinha, Strength and Behaviour of historic masonry under lateral loading. Proc. I.B.Ma.C, Amsterdam, vol. 1, pp. 277-284, 2004.
[19] R. Capozucca, and B. P. Sinha, Evaluation of Shear Strength of Historic Masonry. Proceedings of $5^{\text {th }}$ AMCM, (CD-ROM). Gliwice, Poland, 2005.

[20] A. Anzani, L. Binda, A. Fontana, and S. J. Pina-Henriques, An experimental investigation on multiple-leaf tone masonry, Proceedings of $13^{\text {th }}$ International Brick and Block Mmasonary Conference, Amsterdam, 2004.

[21] S. J. Pina-Henriques, P. B. Lourenço, L. Binda, and A. Anzani, Testing and modelling of multiple-leaf masonry walls under shear and compression, Proceeding of IV International Seminar Structure Analysis of Historic Constructions, Padova, 2004, 299-310.

[22] European Committee for Standardisation, EC6, Design of masonry structures. Part 1-1: General rules for buildings - Rules for reinforced and un-reinforced masonry, ENV1996 1-1: Bruxels: CEN, 1995.

[23] ASTM Specification test methods practices classifications and definitions. E 519-74, 1981, Standard test method for diagonal tension in masonry assemblages, 1862-68.

[24] Samarashinge W. The in-plane failure of brickwork. PhD Thesis, University of Edinburgh,1980, U.K.

Received: June 15, 2011

Revised: August 25, 2011

Accepted: August 30, 2011

(C) R. Capozucca; Licensee Bentham Open.

This is an open access article licensed under the terms of the Creative Commons Attribution Non-Commercial License (http://creativecommons.org/licenses/by-nc/3.0/) which permits unrestricted, non-commercial use, distribution and reproduction in any medium, provided the work is properly cited. 